\title{
Understanding the Public Acceptability of Road Pricing and the Roles of Older Age, Social Norms, Pro-Social Values and Trust for Urban Policy-making: The Case of Bristol
}

\author{
Alexandros Nikitas $^{\mathrm{a}}{ }^{*}$, Erel Avineri $^{\mathrm{b}}$, Graham Parkhurst $^{\mathrm{c}}$ \\ ${ }^{a}$ Department of Logistics, Operations, Hospitality and Marketing, Huddersfield Business School, \\ University of Huddersfield, Queensgate, Huddersfield HD1 3DH, UK \\ ${ }^{b}$ AFEKA, Tel-Aviv Academic College of Engineering, Afeka Center for Infrastructure, Transportation \\ and Logistics (ACITRAL), 38 Mivtza Kadesh St, Tel-Aviv 699812, Israel \\ ${ }^{c}$ Centre for Transport \& Society, Department of Geography and Environmental Management, \\ University of the West of England, Frenchay Campus, Coldharbour Lane, Bristol BS16 1QY, UK
}

\begin{abstract}
:
Cities looking to embark on more sustainable development pathways may need to evaluate the controversial but usually impactful measure of road pricing as a means of reducing their reliance on conventionally fuelled automobiles. Understanding the mechanisms determining the public acceptability of road pricing could be critical for its implementation. Studying the attitudes of older people is of particular significance because of their increasing demographic and political importance and vulnerability to transport-related social exclusion. Prior research identified that older people's social norms and pro-social values affect their attitudes to road pricing. The present paper extends this understanding based on the results of three focus groups conducted in Bristol, UK. According to these, there are three distinctive expressions of pro-sociality: pro-environmental values and generativity, which are mainly drivers of support for road pricing and pro-equity values, which are mainly drivers of opposition. Social norms have two particular expressions; subjective norms (i.e. norms reflecting participants' immediate social environment) and norms about others and society in general. Furthermore, a theory-driven thematic analysis indicates that trust on the integrity of the concept and older age as a life stage associated with ageing, retirement, lower income, mobility barriers and deteriorating health are important in how attitudes reflecting and affecting public acceptability to road pricing form. Finally, the paper highlights the need for packaging road pricing with measures looking to promote its pro-social potential and the importance of peer-to-peer communication and accepting citizens as "social influencers", tailored consultation, pro-social branding, pre-implementation trials, clear administrative roles, transparency, and "political patience".
\end{abstract}

Keywords: Road pricing; Congestion charging; Attitudes, Pro-social value orientations and social norms; Public acceptability; Older people and ageing; Urban transportation planning and policy

*corresponding author 


\section{Introduction}

Road pricing is a travel demand mechanism detailed as long ago as 1844 (Ison and Rye, 2005) aimed at making the allocation and use of existing road space in congested cities more efficient. Nikitas et al. (2011) define road pricing as a concept that covers a range of policy measures, which involve payment for road access in direct relation to usage criteria, rather than paying a fixed network access fee unrelated to use, or paying proxy charges such as road fuel duty. It is widely recognised that road pricing could be an effective measure to solve environmental and congestion problems in urban areas; an instrument that would also normally generate a net welfare surplus (Eliasson and Mattsson, 2006), provide funds for needed roadway and public transit investments (Börjesson et al., 2012) and improve air quality (Coria et al., 2015). Moreover, the changing technologies of road transportation, notably the promotion of electric vehicles, which have (currently) higher fixed costs of ownership and lower variable costs of use, threaten to increase road traffic levels whilst reducing taxation revenues from the sale of liquid fossil fuels, on which many governments have come to rely (Johnson et al., 2012; Parkhurst, 2002;). As a whole, road pricing is traditionally acknowledged as a first-best solution or benchmark for containing externalities and optimising traffic flow (Seik, 2000). Most of the cities which have implemented road pricing schemes, namely Singapore (1975), Rome (2001), Durham (2002), London (2003), Stockholm (2006), Valletta (2007), Milan (2008) and Gothenburg (2013), have according to May et al. (2010) achieved reductions in traffic entering the charging zone in the range of $14 \%$ to $23 \%$.

Despite being a theoretically well-developed transport policy based on a sound economic rationale, which has been successful when applied, road pricing has proven notoriously difficult to decide and implement (Orski, 1992; Sørensen et al., 2014). With exceptions such as those few cities noted above, efforts to introduce significant reform in charging for road use have fallen largely on politically non-supportive ears (Hensher and Bliemer, 2014). This is because politicians tend to see road pricing as a complicated, controversial charge for something that has typically been free (Jones, 1998; King et al., 2007) and as a measure that would receive limited public support; being an "infringement" on freedom of access (Jakobsson et al., 2000). The potential discontent from the motoring public that could put in danger the possibility of re-election has therefore prevented politicians from introducing road pricing (Santos and Rojey, 2004).

The low public acceptability of road pricing thus is one of the strongest barriers hindering its applicability (Fujii et al. 2004; Langmyhr, 1997; Schade and Baum, 2007), with the most important reasons for opposition being social or moral norms of fairness and freedom of choice (Jakobsson et al., 2000). Imposing a cost on something that used to be free at the point of use, such as access to roads during peak driving times which usually, despite some exemptions, is fixed, raises equity issues, especially when considering the likely impacts on exclusion from mobility opportunities and those groups of people more susceptible to them (Ecola and Light, 2010; Rajé, 2003; Rajé et al., 2004). Nikitas et al. (2011) provided evidence that according to the extent to which schemes are identified as having net exclusion-reduction benefits and are seen as "pro-social" the more likely it is that they will be sustained through the implementation process.

The acceptability of any respective system has been seen primarily as determined by attitudes (Schade and Schlag, 2003) and influenced by local scheme-specific characteristics (Grisolía et al., 2015). In many cases the social psychological Theory of Planned Behaviour (Ajzen, 1991), which conceptualises a causal relationship between attitudes and behaviours, has been used as a theoretical basis or as a starting point for forming a more subject-specific theoretical perspective. Although at present a theory of general acceptance does not exist, it is undisputed that attitudes are of great relevance for agreeing or disagreeing with something (Schade and Schlag, 2003). This is why developing an in-depth understanding of the public attitudes to road pricing is crucial in cases where implementing road pricing is a viable policy-making scenario. In this context, studying the attitudes of older people is of particular importance 
because of their vulnerability to transport-related social exclusion, their increasing dependence on automobility, their unprecedented demographic growth and their high political engagement (Nikitas et al., 2011; Rosenbloom, 2001). This is because some of them could be potential "losers" from such an introduction; being among those unable to afford paying more for accessibility by car (Richardson et al., 2010).

Henceforth, the paper provides, in the next section, a more detailed background justifying the need for this study and a synopsis of some key results from previous studies of relevance: it is important in particular to link this work with the authors' previous research, which provided evidence that older people's attitudes, pro-social value orientations and social norms referring to the acceptability of road pricing are of a distinctive character when compared with those of younger people. This is followed by a description of the methodology employed. The core section of the paper presents a detailed report of the key findings of the qualitative analysis. It informs the reader on how attitudes relate to social norms and pro-social value orientations and provides a classification for them. This section also examines the ways with which old age per se and other ageing-induced characteristics like retirement, health, time flexibility and income can influence this social psychological process and the critical role that the lack of trust in public authorities can have. Finally, the paper concludes with a section that integrates the findings by presenting a normative framework that describes how attitudes (and particularly older people's attitudes) towards road pricing may form, thereby providing relevant policy recommendations for the adoption of the measure.

\section{Theoretical and empirical background}

This section aims to describe the theoretical and empirical background of the study. Relevant points of a broad and diverse literature are identified and synthesised in a way that assists the understanding of the study's primary research contributions. The latter will be presented, analysed and discussed in the following sections, with links to existing knowledge drawn out.

\subsection{Defining older age}

While there are commonly-used definitions for framing older age, usually relating to retirement age, there is no universal consensus about a specific chronological threshold at which a person becomes old. At the moment, the United Nations agreed reference point is 60 years or older (World Health Organization, 2017a). The UK Department for Transport (DfT) has linked the eligibility for free, off-peak, local bus travel to the state pension age, which is currently in transition. Prior to that pensionable age was 60 years for UK women. Given that the data collection was conducted in Bristol, UK the age of 60 was selected as the most applicable reference point for marking "older age". Nikitas (2010) reviewed a significant number of studies and proposed that older people could be classified in two categories; those aged 60 to 74 years old ("young older people" or "younger old") and those aged 75 years old and over ("old older people" or "older old"). These definitions have been adopted for the present paper.

\subsection{Why focus a study of road pricing on older people?}

Over recent decades, ageing has emerged as a socio-demographic phenomenon unprecedented in human history for both the developed and developing world. The number of people aged 60 years and over has doubled since 1980 and by 2050 the global population of seniors is projected to be close to 2 billion, with almost 400 million of these people being aged 80 and older (World Health Organization, 2017b). It is notable, then, that older people are more interested in local democracy (Jordan and Avineri, 2008) usually being over-represented in community activity and engagement (Shergold et al., 2012) and more likely to vote than younger people (Goerres, 2007; 2008). Thus it can be hypothesised that their views may be particularly influential on social policy in general, and on the acceptability of road pricing in particular. 
There is another important dimension to older people's emergence as a significant factor in urban policy-making: older people have been identified by various studies (e.g. Gaffron et al., 2001; Hine and Mitchell, 2003; SEU, 2003) as the age group most likely to be subjected to transport-related social exclusion. Social exclusion, widely appreciated as a concept difficult and complex to fully describe, has given a new impetus according to Özkazanç and Sönmez (2017) to the discussions of disadvantageousness and inaccessibility with urban transport being one of its most important determinants. Social exclusion in old age is conceptualised, according to Scharf et al. (2005), as a multi-dimensional phenomenon comprising: exclusion from material resources; exclusion from social relations; exclusion from civic activities; exclusion from basic services; and neighbourhood exclusion.

Although older people tend to make fewer trips overall and the proportion of trips made by car also declines significantly from age 60 (Lucas, 2006), as Langford (2001) argues, "the need for mobility does not cease with old age". Increased longevity and better health and social care enable older people to remain mobile for much longer than ever before (Musselwhite and Haddad, 2010). Excessive restriction of older people's mobility will be detrimental both to society generally, which will become increasingly dependent upon expenditure by older citizens, and to the individual, who will have reduced access to services and social facilities (Langford, 2001). Lack of mobility can prevent older people from participating in most forms of social interaction and lead to low morale, depression and loneliness. This can also impact upon older people's carers, social services and health agencies and perhaps relatives and friends (DfT, 2001). Indeed, the rise of internet-based services, such as home banking, and home delivery of a wide range of goods has made essential services more available for many older people, but therefore placed greater emphasis on mobility outside the home being for social interaction and engagement, rather than fulfilling basic needs (Parkhurst et al., 2014). However, Shergold and Parkhurst (2012) found low levels of self-reported social exclusion in a study of rural elders, indicating that exclusion affects a small if important minority.

Due to the broad-range definition of older age, older people are a particularly heterogeneous group (Fennel et al., 1993). Nevertheless, older adults still have much in common in terms of the biological, psychological and social dimensions, despite their individual differences (Fisk et al., 2009). The literature identifies a number of factors by which older people as a group differ from younger adults and which could be indicators of their potential to form distinct attitudes, including to road pricing. For example, older people are the individuals most likely to have complex mobility needs (Alsnih and Hensher, 2003; Siren and Hakamies-Blomqvist, 2004), physical vulnerability and health issues (Musselwhite and Haddad, 2010; Prince et al., 2015), cognitive limitations in their processing capacity (Kovalchick et al., 2004), concerns about their flexibility and personal safety (Sochor, 2014) and lower annual incomes (OECD, 2013); although this latter point needs to be considered in the context that people over 60, on average, have accumulated more wealth than people under 40 (Eisma et al., 2004).

Older people are also more reluctant to be exposed, start using or accepting new technologies than younger adults (Niehaves and Plattfaut, 2014; Raymundo, and da Silva Santana, 2014; Selwyn, 2004) although given the wide adoption of new information-communication technologies in recent years, this may represent in part a cohort effect. Even if this is the case, there is still a lack of participation by (or perhaps opportunity for) older people in shaping technological development (Sochor and Nikitas, 2016). Older people are also prone to experience a progressive loss of feeling independent with age (Orimo et al., 2006) and they might face ageism by institutions and in interactions with other people in transport settings (Nordbakke and Schwanen, 2014).

In terms of car usage, today's older people are more likely than previous generations to need the use of a car to fulfil mobility needs (Rosenbloom, 2001) and those that have access to cars tend to have car-dependent lifestyles (Badland and Schofield, 2005). Nonetheless, at the same time, seniors can be more cost-aware and more likely to reduce car ownership or use than younger people (Dominy and Kempson, 2006). They are also more likely to rely on others for lifts (DfT 2001; Raje 2003). On the other hand older people enjoy greater time flexibility 
being free from employment and childcare commitments (Siren and Hakamies-Blomqvist, 2004) meaning that they can avoid peak traffic hours and, in many countries, benefit from concessionary travel passes or reduced fares on public transport (Preston, 2012).

It should be also noted that this paper is not examining solely the attitudes of older drivers but the attitudes of older people as a whole (drivers and non-drivers) since individuals that might not drive or own a car could still have an important influence on it, through a referendum process, for example.

\subsection{The social context parameters}

The social dimension is important in the formation of attitudes to road pricing. According to Schade and Baum (2007), negative social norms and perceived unfairness can potentially be factors determining the degree of acceptability. The present paper explores the connection between attitude development and two important elements of social context: social norms and pro-social value orientations.

The proportion of people that tend to favour what is positively valued for society, and assign more importance to collective consequences - a process described as "pro-social value orientation"- has been reported to increase with age (Van Lange et al., 1997). Older people are more likely to be helpful (Midlarsky, 1991) and devote more time to volunteering (Morrow-Howell, 2010), not simply because they have more time, but because they see volunteering as active and meaningful leisure (Chambré and Einolf, 2008). Other research suggests that older people tend to have stronger feelings of solidarity towards needy people than younger people do (Van Oorschot et al., 2005). There is also some evidence that older people may show stronger connectedness to nature, show greater willingness for action at the societal level, and have more supportive recycling attitudes and behaviours (Park and Smardon, 2009). Generativity goals, such as becoming a "keeper of the meaning" or "taking responsibility for future generations" have been found to be most prominent in older age (Dávila and Diaz-Morales, 2009). McAdams et al. (1998) and Lang and Carstensen (2002) suggested that a strong commitment to generativity goals later in life may reflect a desire for "symbolic immortality". Hence in a transport context, older people may be more likely to approve or disapprove of road pricing, depending on whether they believe it would be good or bad for others or for society in general.

This tendency to cater for others, or at least care for what others need, leads to a second hypothesis, suggesting that their beliefs about what family and friends, but also society as a whole, consider to be the normal or acceptable attitudes could influence how older people view road pricing. Thus, social norms defined as "standards of behaviour that are based on widely-shared beliefs about how individual group members ought to behave in a given situation" (Horne, 2001) need to be studied too, especially since there is evidence suggesting attitudinal dependence on social influence (Ajzen, 1991; Oliver and Bearden, 1985).

\subsection{Previous work providing the foundations of the present study}

Although "ageing and mobility" is now a clear theme in city planning and transport policy, only limited research has been published on how older people view road pricing and why they do so. Findings relating to the London Congestion Charge suggested that older people are more positively oriented to road pricing than younger individuals, whilst evidence from Scotland indicated exactly the opposite (Nikitas et al. 2011). Secondary analysis of three datasets: two about the unrealised scheme for Edinburgh (rejected at a referendum in 2005) and a national one examining the concept in general in the UK, provided only inconclusive evidence that attitudes to road pricing vary with age and no explanations about this deviation (Nikitas 2010; Nikitas et al. 2011). Therefore, primary research, considering pro-sociality and social norms directly, was necessary. 
By analysing the answers of 491 survey respondents (including 184 older people) Nikitas et al. (2011), provided evidence that there are age-specific differences in the way older and younger people view road pricing and that their social norms and pro-social value orientations play a role in this variation. Nikitas (2010) identified that the younger old (60-74) were the individuals most likely to express disagreement with the notion that "road pricing is a good idea". The older old $(\geq 75)$, on the other hand, were more likely to be sympathetic or neutral to this notion. Younger old were the respondents least likely to self-declare that they would accept road pricing even if this would be "helping future generations", "easing people's journeys", "improving local transport alternatives" or "reducing the environmental damage", which were the four specific attitude objects used to frame pro-sociality. In comparison, the older old were more likely than any other group to respond positively to these four pro-social indicators. The younger old were also less likely to think that their significant others perceived "road pricing as a good idea" while the older old were far more likely to be neutrally oriented (primarily) or positive to this statement. Older people as a whole, and especially people aged 75 and over, were more influenced by social norms than younger people were. When asked to rate a statement that "they would accept road pricing if their significant others agreed that this was a good idea", more than half of them agreed or strongly agreed. The present paper develops these quantitative findings further, through an in-depth analysis of how older people's attitudes to road pricing are formed.

\section{Research methodology}

\subsection{Study location: The case of Bristol}

The study area chosen was the administrative district of Bristol City, UK, which has a population of 449,300 residents, with $17.5 \%$ of them being aged 60 and over (Bristol City Council, 2016). Bristol provides an interesting example of a post-industrial city, which is relatively economically successful in the British context, continues to witness ambitious urban regeneration projects and policy interventions targeted at the most deprived areas of the city but at the same time faces pressures of growth particularly linked to sustainability and affordability (Tallon, 2007). According to DfT (2016) Bristol hosted for 2016 alone, 634,992 thousand motor vehicle miles ( $77 \%$ of them referring to private car use) with an average extra travel time spend on roads for each commuter due to congestion roughly equal to 148 hours per year (TomTom, 2016). Bristol has for decades been amongst the British cities at the forefront of the road user charging debate, with the local authorities in the Bristol subregion having undertaken technical investigative and planning work into two different charging schemes. However, for strategic political reasons, neither of these schemes has progressed beyond initial, informal public consultation. The concept of charging has therefore shown fluctuating importance in the local transport debate, but there has not been an election mandate sought specifically in connection with charging, as in London, or a referendum held, as in Edinburgh and Manchester. Nonetheless, the level of awareness generated about road pricing by these efforts was regarded as adequate to ensure that social norms and attitudes per se towards road pricing were meaningful (i.e. the attitude object is a sufficiently known quantity for robust social norms to exist).

\subsection{The choice of focus groups}

Focus groups were selected over other qualitative methods as allowing a large amount of interaction between participants so that they could build on one another's responses, exchanging anecdotes, views and experiences, expressing ideas that otherwise may have been unheard and acting as checks and balances to each other identifying factual errors or extreme views (Morgan 1997). Since road pricing was not a measure with which the study subjects had a real-life "connection" on a daily basis, and perhaps not all of them would know where to start from, focus groups was the qualitative method helping them the most to engage in a meaningful and "rich" in terms of data collection dialogue. Kitzinger (1995) suggests that 
focus groups can help people explore and clarify their views in ways that would be less easily accessible in on-to-one interviews and that they can be used to reveal dimensions of understanding, referring among others to group dynamics, which often remain untapped by other qualitative techniques. The focus groups were conducted by a moderator and an assistant moderator. A focus group topic guide (see Appendix) defined procedures and provided consistency between the different sessions. It contained eight parts: introduction; ice-breaker; background discussion items; introduction of scenario type approach; attitudes to road pricing including discussion about age impacts, pro-social values and social norms; spatial, income, trust and media influence discussions; and summing up. All the sessions were audio recorded and transcribed to ensure the accuracy of the participants' insights.

\subsection{Recruitment}

All the focus group participants were selected from a pool of people that had completed the questionnaire of our previous road pricing study (described in Section 2.4) that provided the inspiration for the present work. These people volunteered via answering a recruitment question to take part in a follow-up study at a later time. The researchers made a cautious effort to select a balanced mix of individuals in terms of their attitudes to road pricing but also in terms of their car usage frequency, gender and geographical representation; age was nonetheless the primary selection criterion. The participants were invited to the focus groups initially via telephone with a follow-up in writing. The participants were informed prior to their involvement about the focus groups arrangements. A $£ 15$ incentive was given to them as a token of appreciation. Prior the participants' involvement it was communicated to and agreed with them that the sessions would be recorded and transcribed but the data would be anonymised for confidentiality reasons. Consent for participation and use of the data was obtained. E-mail and telephone reminders were also used (typically two days) prior each participant's allocated session.

\subsection{Employing a scenario-type approach}

A scenario-type approach was employed in which people were presented with a specific hypothetical road pricing scheme situated in Bristol's city centre. This hypothetical scenario was not random; it was based on the design of an unimplemented scheme that was proposed by the City Council in 2000 (after public consultation and a commissioned consultancy) as part of the statutory Local Transport Plan with some minor amendments to cater for the time lapse between the original plan and the present study. The pricing zone of the hypothetical scenario was the one used in the Bristol Local Transport Plan proposal, while costing options were informed by informal discussions with local policy-makers and those running the UK road pricing schemes in London and Durham. The recommended scheme had 14 entry points and includes the city's main Broadmead shopping area, the Centre, West End and Harbourside but excluded the main inner city residential areas. The simulation of a consistent road pricing vision enabled the participants to provide answers in a more systematic way, which would allow meaningful comparisons between the different focus group sessions.

However, during the sessions it was observed that almost all of the participants provided views that were not that closely defined by the geographic characteristics of the scheme per se but were rather characterised by their beliefs referring to the general principles of road pricing as a transport measure employed to battle traffic congestion and air pollution and collect revenue for transport improvements. Thus, although the pricing zone specifics used, allowed the participants to visualise how a road pricing scheme could be adopted by the city, in order to have a benchmark for elaborating thoughts, these did not affect their views about road pricing much; people looked beyond zonal specifics. This explains why geo-spatial design considerations did not arise as a key theme in any of the focus groups. Figure 1 illustrates the hypothetical scheme used. 


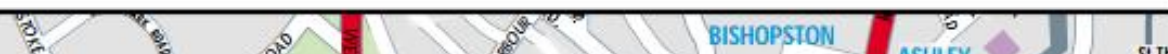

A weekday road user charge of $£ 4$ operating strictly during morning-peak hours (7-10 am) and collected automatically was assumed. Motorists would pay the toll only once per day if they crossed the black line or if they drove within the designated area. Public transport and emergency vehicles and all blue badge holders (i.e. disabled people with special permits) were excluded from paying, while people living inside the charge area and low paid workers (statutory minimum wage) would pay a reduced charge (75\% and 50\% discounts respectively).

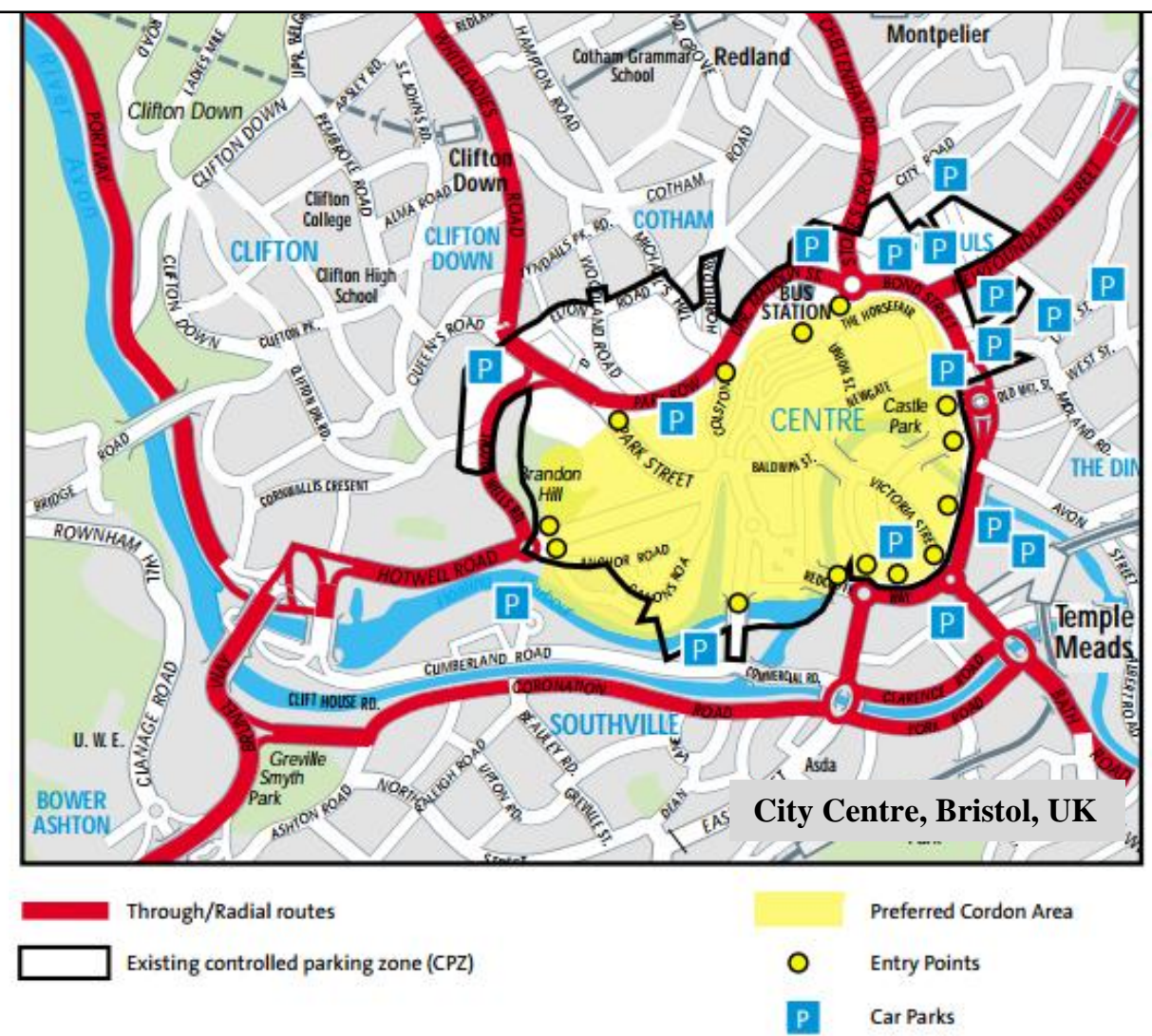

Fig. 1. The Hypothetical Road Pricing Scheme (Bristol City Council, 2000)

\subsection{Method of analysis}

Theory-driven thematic analysis was employed for analysing the data collected. This type of analysis has generally been poorly demarcated and its use rarely acknowledged, yet it is a widely used and efficient qualitative analytic method (Boyatzis, 1998). The method chosen adopts Braun and Clarke's (2006) six-step procedure:

\section{Familiarising with the data through transcription; \\ 2. Generating initial codes; \\ 3. Searching for themes; \\ 4. Reviewing themes; \\ 5. Defining and naming themes; and \\ 6. Producing the final written output.}

After the full transcription of the focus groups and the generation of over 50 different thematic codes, a systematic process of selecting the core themes took place. Throughout the analytical procedures, care was taken to ensure that the extraction and interpretation of findings were based on the raw data rather than on the researchers' impressions. The four themes chosen are, in principle, the four main attitude-shaping parameters that reflect and 
affect older people's acceptability to road pricing. It should be acknowledged that this analysis was analyst-driven on the basis that its focus was on generational differences, older age, pro-social value orientations and social norms. A different thematic analysis (entirely data-driven, for instance) could have led to the emergence of a completely diverse set of themes, such as the linkage of the acceptance of road pricing with the provision of public transport or parking issues.

\subsection{Sampling characteristics of the focus groups}

The sample consisted of 30 participants split into three focus groups each hosting 10 participants. These sample size and group size choices are in line with the best practice literature. According to an evidence-based analysis meaning to build a guide for nonprobability sample sizes by answering how many focus groups are enough for a project to be accurate (Guest et al., 2017) three focus groups are sufficient to identify all of the most prevalent themes; at least 80 to $90 \%$ of all themes, even of marginal importance, are discoverable within three focus groups. Also, Fern (1982) suggests that the ideal size of focus groups is between 8 to 12 after he found statistically significant results suggesting that these focus groups generate as many as $36.7 \%$ more ideas than focus groups with four participants. The group had to be small enough for everyone to have opportunity to share insights and yet large enough to provide diversity of perceptions as suggested by Krueger and Casey (2015).

Two of the groups (A, C) comprised both older and younger participants. Although older people were the main focus of this study and thus there were over-represented in the two sessions, this age-mix choice was an intentional feature of the research design in order to encourage intergenerational dialogue and have older people answering questions in an environment resembling the structure of society and its influences more accurately. This was a method to investigate more closely social norms, a parameter highlighted by the authors' previous work as a potentially critical one, associated not only with their peers but with younger people too. Having only older respondents in all our focus groups could "isolate" them from "social influences" that they typically consider in their real-life decision-making and lead to biases that could affect their answers; the goal was not to push older age as a theme but to identify whether this could naturally come out from the discussions.

A third focus group (B) consisted solely of older and pre-older people (aged 55 to 60) was designed to provide a different interpersonal context that could allow a closer examination of older people's attitudinal dependence on age-related issues such as retirement, pensions, ageinduced mobility/cognitive difficulties and free bus passes. The three focus groups generated identical key themes so focus group B was not an outlier session and it was very comparable in substance and thus consistent with the other two.

The balanced mix between people having positive, neutral and negative attitudes to road pricing allowed the participants to express themselves without having the pressure of communicating views to an audience that was particularly in favour or in opposition to road pricing. Hence social desirability bias was minimised.

Table 1 also lists the demographic and attitudinal characteristics of the participants; the latter as recorded from the authors' predecessor survey study (presented in Section 2.4). The table also provides an evaluation of their respective attitudes after the completion of the focus group sessions, to report change (if any). The words in the brackets denote the participants' post-focus group attitudes towards the goodness of the scheme as evaluated by the moderator and his assistant. Due to the much more complex nature of the pro-sociality and social norm concepts only the ones recorded prior to the participants' focus group involvement are reported. 
Table 1

Participants' characteristics and orientations in respect of key constructs of the research

\begin{tabular}{|c|c|c|c|c|c|c|c|}
\hline \multicolumn{8}{|c|}{ Focus Group A (Mixed Sample) } \\
\hline $\mathbf{N}$ & Name & Gender & Age & $\begin{array}{l}\text { Frequency of } \\
\text { Driving }\end{array}$ & Road Pricing Goodness ${ }^{1}$ & $\begin{array}{l}\text { Pro-Social Value } \\
\text { Orientations }^{2}\end{array}$ & Social Norms ${ }^{3}$ \\
\hline 1 & M.L. & $\mathrm{M}$ & 75 & Daily & Agree (Agree) & Agree & Neutral \\
\hline 2 & M.W. & $\mathrm{F}$ & 83 & Daily & Strongly Disagree (Agree) & Disagree & Strongly Disagree \\
\hline 3 & M.C. & $\mathrm{M}$ & 56 & Daily & Neutral (Agree) & Agree & Agree \\
\hline 4 & G.N. & $\mathrm{F}$ & 69 & Weekly & Agree (Agree) & Agree & Agree \\
\hline 5 & P.C. & $\mathrm{M}$ & 66 & Few Times a Week & Strongly Agree (Strongly Agree) & Agree & Agree \\
\hline 6 & J.B. & $\mathrm{F}$ & 70 & Few Times a Week & Neutral (Disagree) & Neutral & Neutral \\
\hline 7 & M.B. & $\mathrm{M}$ & 37 & Few Times a Week & Agree (Agree) & Agree & Agree \\
\hline 8 & A.P. & $\mathrm{F}$ & 26 & Never & Disagree (Disagree) & Agree & Strongly Disagree \\
\hline 9 & C.V. & $\mathrm{M}$ & 33 & Never & Disagree (Disagree) & Disagree & Neutral \\
\hline 10 & M.K. & $\mathrm{M}$ & 47 & Daily & Strongly Disagree (Strongly Disagree) & Disagree & Disagree \\
\hline \multicolumn{8}{|c|}{ Focus Group B (Older and Pre-older Participants Only) } \\
\hline $\mathbf{N}$ & Name & Gender & Age & $\begin{array}{l}\text { Frequency of } \\
\text { Driving }\end{array}$ & Road Pricing Goodness & $\begin{array}{l}\text { Pro-Social Value } \\
\text { Orientations }\end{array}$ & Social Norms \\
\hline 11 & K.M. & $\mathrm{M}$ & 65 & Daily & Strongly Disagree (Strongly Disagree) & Disagree & Disagree \\
\hline 12 & C.T. & $\mathrm{F}$ & 55 & Few Times a Week & Neutral (Agree) & Agree & Neutral \\
\hline 13 & L.S. & $\mathrm{F}$ & 62 & Daily & Neutral (Disagree) & Strongly Disagree & Agree \\
\hline 14 & A.L. & $\mathrm{M}$ & 61 & Daily & Neutral (Agree) & Agree & Agree \\
\hline 15 & J.H. & $\mathrm{M}$ & 57 & Never & Disagree (Disagree) & Disagree & Neutral \\
\hline 16 & B.S. & $\mathrm{F}$ & 78 & Never & Agree (Agree) & Strongly Agree & Neutral \\
\hline 17 & P.R. & $\mathrm{F}$ & 68 & Few Times a Week & Strongly Disagree (Disagree) & Agree & Disagree \\
\hline 18 & N.C. & $\mathrm{F}$ & 61 & Never & Strongly Agree (Strongly Agree) & Strongly Agree & Strongly Agree \\
\hline 19 & O.M. & $\mathrm{F}$ & 75 & Never & Strongly Disagree (Disagree) & Strongly Disagree & Strongly Disagree \\
\hline 20 & J.R. & M & 72 & Few Times a Week & Neutral (Neutral) & Agree & Neutral \\
\hline \multicolumn{8}{|c|}{ Focus Group C (Mixed Sample) } \\
\hline $\mathbf{N}$ & Name & Gender & Age & $\begin{array}{l}\text { Frequency of } \\
\text { Driving }\end{array}$ & Road Pricing Goodness & $\begin{array}{l}\text { Pro-Social Value } \\
\text { Orientations }\end{array}$ & Social Norms \\
\hline 21 & V.W. & $\mathrm{F}$ & 64 & Few Times a Week & Disagree (Disagree) & Agree & Disagree \\
\hline 22 & D.H. & $\mathrm{M}$ & 75 & Few Times a Week & Neutral (Agree) & Neutral & Neutral \\
\hline 23 & T.J. & $\mathrm{M}$ & 64 & Few Times a Week & Strongly Disagree (Disagree) & Disagree & Strongly Disagree \\
\hline 24 & M.G. & $\mathrm{F}$ & 84 & Never & Neutral (Agree) & Strongly Agree & Neutral \\
\hline 25 & E.H. & $\mathrm{F}$ & 79 & Daily & Strongly Disagree (Disagree) & Strongly Disagree & Strongly Disagree \\
\hline 26 & A.W. & $\mathrm{F}$ & 62 & Few Times a Week & Strongly Agree (Strongly Agree) & Strongly Agree & Strongly Agree \\
\hline 27 & T.V. & $\mathrm{M}$ & 29 & Never & Disagree (Disagree) & Disagree & Agree \\
\hline 28 & K.M. & $\mathrm{F}$ & 30 & Weekly & Agree (Agree) & Neutral & Strongly Agree \\
\hline 29 & J.R. & $\mathrm{M}$ & 31 & Weekly & Agree (Agree) & Strongly Agree & Neutral \\
\hline 30 & R.A. & $\mathrm{F}$ & 32 & Weekly & Agree (Agree) & Agree & Agree \\
\hline
\end{tabular}

${ }^{1}$ Reflects the response to an item suggesting that "road pricing is a good idea"

${ }^{2}$ Reflects the response to an item suggesting that "I would accept road pricing if this helped easing people's journeys"

${ }^{3}$ Reflects the response to an item suggesting that "I would accept road pricing if my significant others agreed that this was a good idea" 


\section{Results and analysis}

Piecing together the overall picture was not simply about aggregating patterns, but as Musselwhite (2006) suggests, a process of weighing up the salience and dynamics of issues, and searching for structures within the data that have explanatory power, rather than simply seeking a wealth of evidence. The selection of findings is based on raw data to reduce analystrelated biases; this is why for each of the key points made by the authors one (or more) of the most representative respondent extracts, highlighting this particular point, is used. According to Braun and Clarke's (2006) and to Vaismoradi et al. (2013) the selection of the most vivid and compelling extract examples of individual responses is a precondition for reporting results when employing a thematic analysis framework; these should generally be preferred over analyst-deduced summaries of quotes which is a more quantitative approach.

There were four core themes that the data analysis signified as being important factors in the attitude-shaping process of the older (and younger to some extent) people for the stimulus of road pricing: pro-social value orientations; social norms; trust; and (older) age. For each of them the researchers identified a number of distinct expressions that impact on attitudes.

\subsection{Pro-social values}

Pro-sociality can be distinguished according to the present analysis to three distinctive expressions: pro-equity value orientations, pro-environmental value orientations and generativity. There is no literature or previous theory that has identified all three of them as the three key forms of pro-social value orientations; this is the first time pro-social value orientations are analysed to this degree and a classification approach is proposed. Nevertheless, these pro-sociality forms have been recorded independent from each other either as reasons behind volunteering or as expressions of willingness for action at societal level, not with the terminology used herein necessarily and not in relation to older people: pro-equity value orientations (Van Oorschot et al., 2005; Young and West, 2010), proenvironmental value orientations (Joireman et al., 2001; Park and Smardon, 2009) and generativity (Dávila and Diaz-Morales, 2009; Morselli and Passini, 2015; Timilsina et al., 2016).

Pro-equity values: Participants primarily expressing pro-equity concerns were likely to assess road pricing strictly in financial terms, labelling it as "yet another form of taxation" and disagreeing with the policy. Most of them were older people reporting to have witnessed, over the years, policies "supposedly linked with societal benefits" repeatedly failing to deliver any pro-social outcomes. They expected that road pricing would be unfair, especially for people susceptible to social exclusion. Some of them specified that because they care for their fellow citizens they would not favour a scheme that could produce adverse distributional impacts.

"Some of us on this table have free bus passes so why bother about road pricing?" Moderator

"There are still poor people that are younger. It would hit their pockets and they probably would not be able to afford a car!" O.M., aged 75

These participants suggested that the policy-makers need to address adequately the design of any eventual scheme in order to ensure that this will be truly equitable. Only if they could operate a scheme not depriving the less-affluent members of society from access to the city centre would this be an acceptable policy for them.

"Road pricing must be egalitarian; you need to form it so that the poorer people do not really lose out" A.W., aged 62 
Nonetheless, there were a few exceptions of pro-equity value-oriented people who evaluated "costs" based on time and liveability considerations. These individuals suggested that a "fairer" reallocation of road space, prioritising people and public transport over automobiles, which may lead to less travel delays and more traffic-free, accessible and thus liveable cities, is a matter of equity too.

"If you take the example of London, public transport has been vastly improved in the centre since the introduction of road pricing. Also, in places which are traffic-free the businesses prosper beyond measure. People want to go there because these places are pleasant. They do not have to get their cars, they do not have to pay for parking." P.C., aged 66

Pro-environmental values: Pro-environmental value orientations represent the second expression of pro-sociality. Environment was a principal concern for about $20 \%$ of the participants, although when many of them were prompted about the environmental disbenefits of traffic they exhibited pro-environmental thinking. People that consistently articulated environmental considerations were generally positive to road pricing. People aged 34 or younger and especially young parents were the ones that usually initiated discussions around environmental concerns meaning that Park and Smardon's (2009) notion that older people may show stronger connectedness to environmental matters was not necessarily true in this scenario. The following extract example is the response to an older people-driven pro-equity dominated discussion that entered environmental considerations in the on-going dialogue.

"My husband and I would probably approve of anything that takes cars off the road and protects the environment and we would not necessarily think whether it was socially equal or whether it was penalising people!' K.M., aged 30

Nonetheless, there were some older participants that talked about environmental sustainability when discussing the policy's acceptability.

"We are aware of what damage we are doing to the environment in our household. And I do not know why other people are not aware of it but we feel very strong and that is why we are cyclists, we are walkers and I use my bus pass every day, sometimes more than once a day." N.C., aged 61

Issues, like "green development", "ecologically friendly transport" and the need for battling "CO $\mathrm{O}_{2}$ emissions and air pollution" and "climate change" came up during the sessions both spontaneously and after trigger questions. Clearly older people seemed to care a lot for the environment although they were not as passionate as some younger people. Nonetheless, on most occasions this was the case just because they did not recognise the potential proenvironmental benefit that road pricing could offer. They considered that "a local road pricing scheme's environmental benefit would be minimal" compared to the potential adverse equity issues discussed.

Generativity: Some participants referred extensively to the effect that "a bad transport system could have on children and on future generations" and related these thoughts to their personal assessment of the policy in focus. People expressing generativity-related insights were usually positive to road pricing.

"If we do not do something with road traffic now, or soon, we are going to be in trouble. It will not affect me. I am too old (laughter)!” M.L,, aged 75

"Yes some of my respondents suggested that this measure would help future generations to enjoy a better environment." Moderator

"I would say this is our duty." M.L., aged 75 
Nevertheless, there were participants negatively oriented to road pricing who expressed these concerns but still could not see how the proposed measure could help future generations.

"It is true that the centre of Bristol is polluted and we know that the stuff in petrol affects the brain of children and may harm future generations... but I am not sure that this scheme is going to actually do a lot towards that...because as somebody has already said people will continue to use their cars." J.B., aged 68

As a whole, the older participants were far more likely to express thoughts relating to generativity than younger people. Older people having a longer time perspective witnessed the deterioration of traffic conditions over the years, whereas younger people have not experienced lower-traffic times; this experience allowed senior citizens to consider possible a less car-dominated future for their city and for "their children and grandchildren". Older people, being individuals with increased awareness of mortality (Maxfield et al., 2014), felt that being closer to the end of their lifespan meant that they had an increased responsibility to cater for the needs of the future generations and perhaps sacrifice some of their needs for car travel now for more liveable urban futures.

Among the young participants, only two mothers with young children specifically expressed concerns about the impact that the current traffic situation might have on their children. This was the case since the upbringing of their children, and thus caring for future generations, was something personal and of recent direct experience to them; in this sense they were somewhat similar to older participants. There is evidence (Tabuchi and Amira, 2015) suggesting that older people's generativity is more evident when they are exposed to intergenerational interaction; thus the inclusion of younger people in the focus group sessions helped capturing better this phenomenon.

These particular pro-social findings mean that much as previous research has shown (e.g. Hofer et al., 2014; McAdams et al., 1998) generativity seriously affects older people's attitudes and intended behaviour.

\subsection{Social norms}

Social norms emerged as another determinant of attitudes to road pricing. This is in line with recent literature studying the factors that influence older people's attitudes to technology suggesting that family, friends and peers can positively or negatively influence acceptance (Peek et al., 2014). The social norms of the present study could be separated into subjective norms and the norms of others. Subjective norms are the norms referring to the people that are most important in one's life; usually family and friends (Azjen, 1991). The norms of others could be a more legitimate pro-social indicator since they reflect the views of the general public, referring to people not directly related to the participants.

Many of the older participants, when asked directly, declared that their attitudes were not influenced by others, not even by people close to them, because "they can decide for themselves".

"No! I have my own opinion and I am rather strong about it! So what other people choose to do, well that is their right to say what they want." M.W., aged 83

Nonetheless, even without acknowledging this influence they showed genuine interest about what other people thought of the measure.

"I am just trying when thinking about it to refer to people about my own age. I still have a lot of friends who drive but they would not need to go; I mean they are not working, they would not need to go at that little bit of time (meaning the charge period). So they would not be bothered; I would not personally!” M.G., aged 84 
There were numerous examples of older participants talking specifically about their relatives and friends while expressing their attitudes to road pricing; thus the need to specifically identify subjective norms as a distinct type of social norms. Many of them thought that their personal views were identical to those of the people they used as a reference point.

"Well I think I am not influenced by anyone either, but I have known opinions about it, and I am in favour of road pricing and my husband is in favour and I think my children would be as well." N.C., aged 61

In this case, an older participant supporting road pricing considered herself to have decided completely independently from anyone else that she was in favour of the policy. However, at the same time she did not fail to recognise that the people most important to her (i.e. family) would have also been in favour of road pricing. This hypothetical "family support" of her position could have played an implicit role in the development of her attitude towards the proposed scheme. Her subjective norms thus could be one of her main decision-making factors even if she does not seem to recognise this influence.

The older participants generally seemed to be influenced by social norms, although at the same time they were the people most likely to point out that "they were independent thinkers". This finding provides explanatory support to the statistical findings of Nikitas et al. (2011), suggesting that older people are more likely to be influenced by social norms than younger people. It should be pointed out, however, that social influence, is a bi-directional phenomenon so older people can also be "social influencers".

\subsection{Trust}

Lack of trust about the motives behind the introduction of road pricing, its eventual efficiency, ease of use and administration, and about the way that the collected revenues would be spent was a third theme that emerged. Lack of trust had a clearly negative effect on the attitudes, pro-social value orientations and social norms of the focus group participants; the participants expressing these feelings suggested that mistrust was the main reason they were against the scheme. Trust has also been reported as being a key motivation for underlying opposition to the scheme rejected for Edinburgh (Gaunt et al., 2007; Scottish Executive, 2006), particularly for older citizens (Nikitas, 2010).

In the Bristol research, almost all the participants agreed that if they were sure that the scheme would provide direct funding for a transport improvement package they would accept it. Most of the participants, and especially those aged 60 to 74, were very suspicious, however, about the motives behind the scheme's implementation and about the eventual misuse of the money generated.

"Councils and Government chop all the money. They always get in these hair-raising schemes and it is all to get money!" O.M., aged 75

Moreover, they did not trust the effectiveness of the chosen methods and planning procedures that the local and national authorities followed in general. For example:

"I doubt that road pricing would ever be implemented. Because we come back to the old story of people having bright ideas, agreeing on a plan of action and then nobody wants to take the final decision. And when they take the final decision, some group comes up and says 'we were not consulted' and so everything is tried out all over again. So five years later you are still not a lot further from where you started." P.R., aged 68

Upfront transport investments with an emphasis on the enhancement of public transport services, transparent fund-raising and expenditure, and more effective administrative 
procedures could re-establish trust. More specifically, the most discussed way to offset "lack of trust" was revenue hypothecation. Most of the participants believed that focused, preimplementation investments on transport alternatives and road infrastructure could make them - and others too - more positive about road pricing. Some participants suggested that "they need proof in advance" that road pricing could be beneficial for society and that it would not be "yet another tax-generator". If these people could see committed revenue hypothecation then they would have been willing to accept a policy that gives value back to society.

"Oh dear! I think if you saw the benefit for what you are having to pay that would be a different matter." M.W., aged 83

The "inefficient" -as branded by some of the participants- way in which transport administration was perceived to operate was a frequent discussion topic. The following extract communicates a strong opinion about the need to package the revenue generated by different road taxes and re-invest it solely on transport through an independent, transparent and decentralised transport administrative body that would have the primary responsibility for these funds rather than other governmental bodies that may undertake multiple other tasks that go beyond transport.

"You know if there was an independent transport department and all funds from road pricing, parking charging went there... and this budget was purely for road and public transport improvements then you could say 'yes let them get on with it'. This should have no relation with any government centre... and use the funds independently." K.M., aged 65

Older participants' lack of trust meant that they could not see road pricing as a measure with a genuine pro-social potential; on the contrary because they feared such a scheme would be handled by authorities as a road tax with a purely anti-social character they expressed their pro-sociality by disapproving of it. Social norms are also built in this way. So, lack of trust negatively affects social norms.

It is notable that the nature of the focus group discussions converted the initial negative attitudes of three older old $(\geq 75)$ participants into support for the scheme; they justified this attitudinal change by suggesting that "they gained trust through the focus group discussions that the measure had a realistic potential to be pro-social".

Hence the dynamics of the qualitative research signalled a potential route to improved citizen perception of road pricing: the importance of peer-to-peer communication rather than expert or authority voices.

\subsection{Older Age}

The fourth core theme, and one that was underpinning the scope of this work, was (older) age; a parameter that had an impact on the attitudes, pro-social value orientations and social norms of individuals but still was not directly acknowledged - especially by the older participants as a factor that could, per se, shape their and other people's attitudes to road pricing. Nonetheless, older age, is immediately linked with a number of factors that the older participants directly recognised as factors affecting their attitudes. These particular factors were: disabilities and mobility problems; general state of health; financial status; resource flexibility (i.e. more personal time and free public transport travel); and employment status (retirement vs employment). Therefore, ageing plays an indirect but, nonetheless, critical role in the development of norms around road pricing for senior citizens.

More specifically, older participants, when asked about the impact that their age might have on their attitudes, suggested that older age is not be as important as mobility or their health to their evaluation processes despite the fact that those three according to literature (e.g. Metz, 2000; Webber et al., 2010) are highly correlated. Lack of mobility, which is a concept generally associated according to Urry (2012) with control, freedom and the possibility to 
make choices, was conceived as a barrier typically referring to kinetic challenges and general state of health; ageing was considered a more random influence factor.

"If you were a bit younger or a bit older what would you think about road pricing?" Moderator

"You cannot tell... can you? Because some people that are in their fifties cannot walk as well as others who are in their seventies. It is not age related as such... is it? It is so random!" T.J., aged 64

\section{"So I guess it is about mobility?" Moderator}

"It is all about mobility! Yes! If you get about it is great!” T.J., aged 64

"Yes! And it is about your general state of health too." E.H., aged 79

Further discussions indicated that mobility challenges and ill health combined with a new road charge could eventually create new layers of transport-related social exclusion for people like disabled pensioners and this could adversely influence attitudes to road pricing, especially those of older people.

Older age, can also impact individuals' financial status, which might have an effect on their ability to pay a road charge or on their beliefs about being able to afford this. If car based travel becomes more expensive for low-income motorists with relatively low values of time because of the introduction of road pricing - the disbenefit of the new charges will outweigh any time savings, resulting in reduced travel (Raje, 2003). The perceived value of pensions therefore was a strong driver of opposition.

"It is only four pounds it will not hit that much your pocket." K.M., aged 30

"You think pensioners will say that: 'It is only four pounds'? No!' N.C., aged 61

Some older people (or retirees as M.C. in the extract provided below) had enjoyed higher incomes when younger, when working. These people might have then been more accepting of a road charge than they were at the time of the research.

"I do not think things bothered you that much when you were younger. Money was not a problem. When you had to be somewhere, and that even if it meant you paid to go on a toll road you did it; even if you did not like it. Now being retired and having different needs... yes you do worry about road pricing more." M.C., aged 56

Some discussions recognised the multiple dimensions with which the older age factor could influence public attitudes to road pricing. Retirement, low income, mobility difficulties and disability in general, even to a lesser extent living in a rural area (older people in the UK are more likely to live in a rural area than younger people) are factors, all highly correlated with age that play a role in the development of older people's attitudes to road pricing.

"Pensioners cannot cover the cost of living so using money that way especially if you are a disabled pensioner is not good... you need your car all the time. If you are a rural pensioner then you are really in trouble because everybody who lives in a rural area depends on their car. I think that the older you get it is harder. It is a fact that you will feel very differently at 70 than what you did at 50... about how far you can walk, how far you can go and how far you can manage without help." J.B., aged 70 
Most of the participants, notwithstanding their age, agreed that people such as disabled pensioners should be exempted from the measure. This could make road pricing a visibly fairer policy that respects social inclusion and could be therefore considered by people exhibiting high pro-equity value orientations as more acceptable. This is in line with the work of Bonsall and Kelly (2005) which suggests that exempting groups vulnerable to social exclusion, including disabled drivers, is important since this is an inclusive approach that cannot compromise the overall objectives of congestion charges.

The time flexibility that retirement provides and their access to concessionary fares (a measure employed to reduce social exclusion amongst older people in the UK) also came up when discussing age-related differences in the way road pricing could impact different road users. The ability of older people to spread out trips throughout the day (Andrews et al., 2012) could be beneficial for them, in theory, in terms of increased opportunities to travel in general and for this study's particular context in terms of avoiding road pricing charges. Some older participants realised this possibility during the focus groups suggesting that a scheme with a charge between 7 and10 am could not penalise financially people that could avoid travelling into the city centre during the morning peak-hour traffic or they could instead use public transport; people like pensioners and free bus-pass holders.

"Pensioners have got free bus cards, so it does not matter. Road pricing or not they can travel anytime." P.R., aged 68

However, even if some identified that older people could "escape" road pricing, the charge was not viewed favourably by the majority of the older participants with pro-equity concerns.

\section{Discussion, conclusions and policy recommendations}

The present analysis has strengthened the argument of Nikitas et al. (2011) that pro-social values and social norms play an important role in how older people form attitudes towards road pricing. Processes by which pro-social values influence participants were identified, and these were especially clear for those aged 60 to 74 . The influence was primarily negative, since pro-sociality for them was an equity attribute reflecting the monetary barrier introduced by road pricing to people with lower incomes or reduced mobility. Older people, however, were at the same time more likely to see pro-sociality as a commitment to what is necessary for providing future generations with a better opportunity to enjoy a liveable city. Older focus group participants reported holding similar attitudes to family and friends. Although they were reluctant to acknowledge being socially influenced, perhaps due to the high value placed on independent personal agency in western society, it seems likely that they are influencing and being influenced by their social networks and wider society.

Lack of trust about the motives behind the introduction of road pricing, its eventual efficiency, ease of use and administration, about the way that the collected revenue would be spent and about its potential for benefiting a local community constituted an important explanation of opposition to the idea of road pricing. Trust is essential for policy innovation, because innovation involves risk but at the same time trust is easier to destroy than to create. Officials who have lost credibility because they are perceived to have broken promises in the past will struggle to convince voters of their sincerity, and therefore will find it very hard to introduce a policy as controversial as road pricing (Manville and King, 2013). Hence, the findings are in agreement with Schmöcker et al.'s (2012) suggestion that "trust in government is a determinant of acceptability" and the work of others (for instance, Di Ciommo et al., 2013; Frey, 2003; Jaensirisak et al., 2005).

Figure 2 below, brings all these findings together and provides a normative model of older people's potential for accepting road pricing highlighting the factors that play a role in their decision-making process. In producing this model, the approach was analyst-driven, drawing upon theories of attitude and social norm development including the Theory of Reasoned 
Action and the Theory of Planned Behaviour, deductively informed (for its initial conception at least) by existing road pricing literature and more importantly by its predecessor questionnaire study described in Nikitas et al. (2011). The figure identifies positive relationships between pro-environmental values and generativity, tending to be drivers of support, whilst pro-equity values have a negative relationship, as they were in most cases, drivers of opposition. Older age, was not recognised by the participants as a direct determinant of acceptability per se but as a parameter influencing a set of factors (identified in the figure) that were deemed crucial in their attitude-building processes.

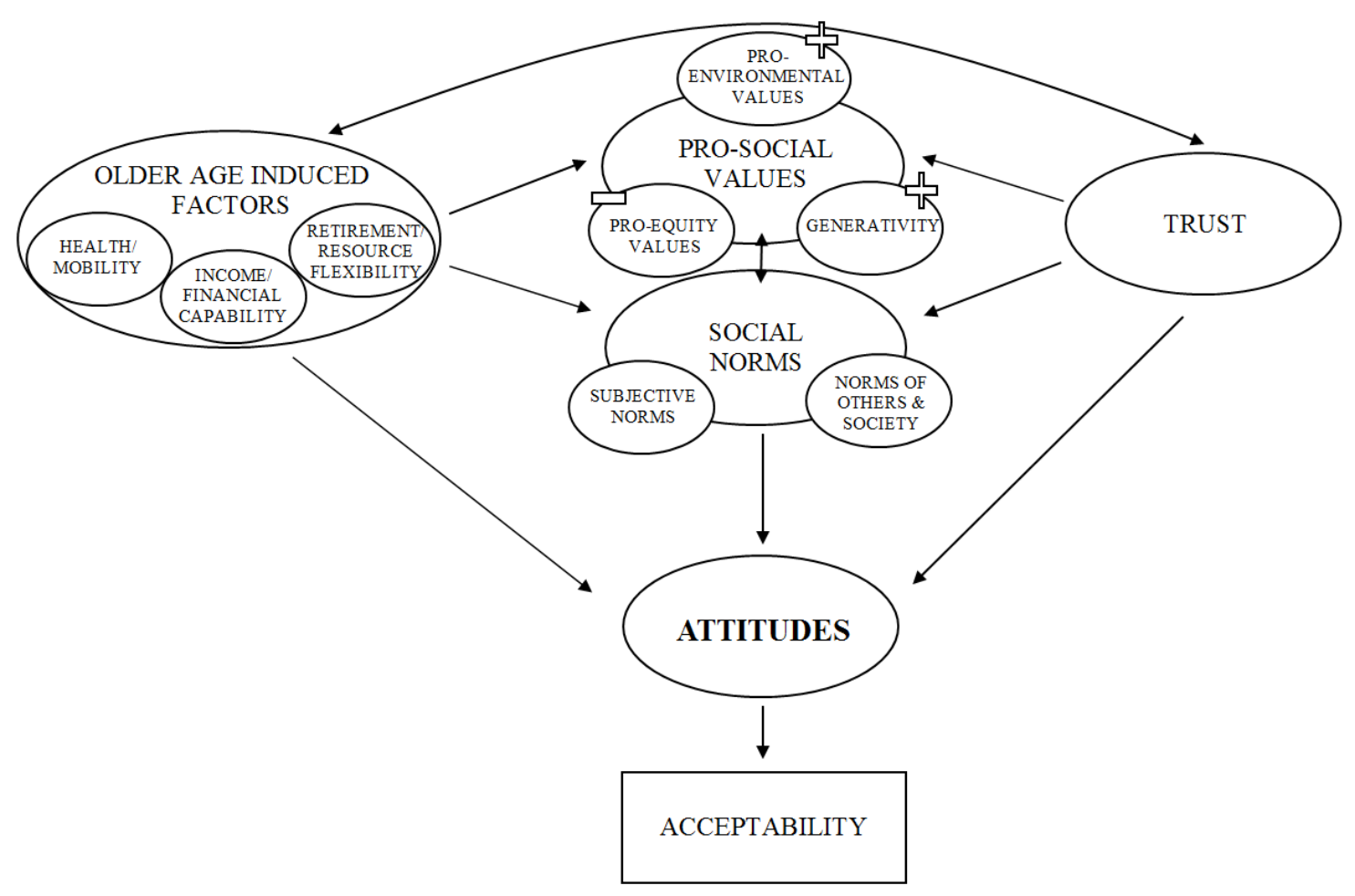

Fig. 2. Older people's attitude-shaping mechanism.

Since the key barriers to any travel demand measure will often be finance, public acceptability, and concerns that some members of society will be adversely affected (May et al., 2006) the present paper informs those involved in managing policy processes, which potentially involve significant change in individuals' lives. Further, it informs those especially involved in developing built and social environments responsive to the aspirations and needs of older people, an objective that according to Buffel et al. (2012) is now accepted as being a major concern for social and public policy.

More specifically, the policy relevance of the normative model includes the need for authorities planning to implement road pricing to be aware that people, and in particular older people, may not always identify its potential as a pro-social measure that can benefit them, their significant others, their local communities or their city as a whole. On the contrary, they might see it as a policy that creates equity imbalance and potentially penalises the poorest and the socially disadvantaged people who depend on car mobility for access to key services and opportunities. A similar argument is legitimate for social norms too; older people and especially those that are personally against road pricing may consider that social norms referring to road pricing are negative.

Therefore, it is necessary for city policy-makers to communicate plans in a sound way that does not focus too heavily on the rather arbitrary and subjective goal of "average welfare 
gains" (Banister, 2003) but instead emphasises the potential pro-social character of the measure for "helping future generations", "easing people's journeys", "improving local transport alternatives" and "reducing environmental damage". This pro-social presentation of the measure will probably make older people less reluctant to accept it. This approach is in line with Pronello and Rappazzos' (2014) recommendation that a clear communication strategy should be defined and should be tailored according to the different groups in terms of their acceptance towards the measure. The role of communication in a road pricing implementation process also incorporates marketing and information considerations; these three are the most critical implementation factors after public and political support, according to Noordegraaf et al. (2014) and cannot be underestimated for authorities looking to adopt the policy.

Integrated transport policy packages involving road pricing, which on its own is always likely to be hard to deliver politically, with other measures that involve: revenue hypothecation; visible upfront transport investments; compensation for potential losers in the form of exemptions, discounts, special permits or concessionary fares for public transportation can support the implementation of road pricing and improve public acceptance. This could help citizens, and especially older citizens, realise that road pricing is an integral part of an overall strategy for improving transport and the means of access and not another tax-collection initiative penalising drivers and restricting the mobility of those at-risk of social exclusion.

Demonstration projects presenting the likely benefits to those affected including forecasting models that predict most likely post-implementation changes and focused public consultation exercises meaning to highlight the measure's pro-social potential and re-establish trust between the policy-makers and the public can also improve the acceptability of a potential scheme. Perhaps "re-labelling" road pricing to "environmental charges" and emphasising their positive effects on sustainability may have an impact on acceptability as Eliasson and Jonsson (2011) proposed; this alternative focus accompanied by a strong campaign about the environmental merits of the measure could perhaps "convince" older people (and other populations), that nowadays seem not to directly associate congestion charges with environmental improvements much, about the pro-environmental potential of road pricing. As a whole, and similarly to what Gehlert et al. (2011) suggests, road pricing packages should be re-defined based on the social background of user groups with a special focus on populations that may be closer to transport-related social exclusion like older people.

Limited-time policy trials with a review point can be a way to create legitimacy before a permanent implementation is agreed; since as one of the study's older respondents put it "if one sees what one has to pay for that would be a different matter in terms of acceptance" a pilot could provide this "see for yourself" opportunity. Winslott-Hiselius et al. (2009) found from Stockholm's road pricing trial that public attitudes became more positive as a whole during the trial as personal experience gave a new understanding of the implications of the charges for personal well-being. From the perspective of the present paper, trials give a "chance" to an unfamiliar and "untested" policy measure that would otherwise face resistance due to insufficient trust to accept a permanent change.

Another strategy for acceptance, associated with the present study's trust-related findings, is for the city policy managers to make their respective roles clear and transparent for every phase of the planning process and eventual scheme management approach and involve civil society organisations, similarly to what Sørensen et al. (2014) suggests, at different stages of the policy-making and implementation process in "formal" roles. Even individual citizens with an interested to be "involved" in these processes should be allowed to follow closely the scheme development. The active involvement, and empowerment, of potential project partners from an early planning stage can also be a way of achieving consensus and support for road pricing; it was one of the success factors reported by Ieromonachou et al. (2004) for the Durham road access charge scheme.

On the one hand, allocating clear administrative responsibilities may simplify the communication strategy, ease public engagement and signify that road pricing is a transparent 
and de-centralised function. On the other hand, the present research emphasises the importance of citizens as "social influencers" and in particular emphasises older people as citizens relatively likely to engage in policy processes and able to influence their social networks. This paper makes the case that citizens, and older citizens in particular, are perhaps more likely to respond positively to peer-to-peer consulting, especially coming from those close to them, supporting road pricing than to trust experts with complex forecasting models.

Investments on ageing-friendly technology per se and supporting mechanisms that could inform and educate older people, that might feel threatened by an impeding scheme of how to surpass user-related challenges, is another way to guarantee that road pricing will not develop to (or that it will not be perceived as) a measure that could create negative distributional effects and societal imbalance. Road pricing technology should be employed, and portrayed in communication and marketing terms for perception-building purposes, not as a cognitively challenging barrier to road access that penalises the older, the poor and the needy but as an opportunity to make mobility fairer and the city a better place for future generations. This is in line with what Sochor and Nikitas' (2016) work on technology and vulnerable populations suggests.

Finally, road pricing policy developers will need to be patient and acknowledge that acceptance is a process that takes time, especially with those citizen groups more interested in conserving the status quo, which are often held to include older citizens. Experiences even from cities that did not have a trial phase to the introduction of road pricing show that once people become familiar with the policy, public acceptance increases (Hysing, 2015). This change reflects the development of attitudes that "the positive effects of the scheme turn out to be larger than expected" or "things did not turn out as bad as feared" (Börjesson et al., 2016; Schuitema et al., 2010). So, as Eliasson (2014) and Goodwin (2006) suggest, people may underestimate the benefits of road pricing ex ante; once benefits appear though, attitudes become more positive.

This means that the pro-social importance of road pricing and thus the formation of more positive social norms is a process that not only takes time and needs "political patience" but in some cases might require a level of familiarity that is produced only via the actual use of the scheme. It is suggested therefore that the real-life outcome of road pricing with respect to various equity and environmental needs, similarly to what Kim (2005) has suggested, especially for vulnerable populations like older people as examined herein, could help overcoming public scepticism.

\section{Acknowledgments}

The authors are grateful for the funding support of the UK Government Department for Transport and Bristol City Council. However, the views expressed in the paper should be assumed to be entirely their own. Special thanks to Dr Ben Clark for assisting the focus group moderation.

\section{References}

1. Ajzen, I., 1991. The theory of planned behaviour. Organizational Behaviour and Human Decision Processes, 50, 179-211.

2. Alsnih, R. and Hensher, D., 2003. The mobility and accessibility expectations of seniors in an aging population. Transportation Research Part A: Policy and Practice, 37(10), 903-917.

3. Andrews, G., Parkhurst, G., Susilo, Y. O., Shaw, J., 2012. The grey escape: investigating older people's use of the free bus pass. Transportation Planning and Technology, 35(1), 3-15. 
4. Badland, H. and Schofield, G., 2005. Transport, urban design, and physical activity: an evidence-based update. Transportation Research Part D: Transport and Environment, 10(3), 177-196.

5. Banister, D., 2003. Critical pragmatism and congestion charging in London. International Social Science Journal, 55(2), 249-264.

6. Bonsall, P. and Kelly, C., 2005. Road user charging and social exclusion: The impact of congestion charges on at-risk groups. Transport Policy, 12(5), 406-418.

7. Boyatzis, R. E., 1998. Transforming Qualitative Information: Thematic Analysis and Code Development, Thousand Oaks, London, and New Delhi: Sage.

8. Braun, V. and Clarke, V., 2006. Using thematic analysis in psychology. Qualitative Research in Psychology, 3, 77-101.

9. Bristol City Council, 2000. Bristol Local Transport Plan: Getting Bristol to Work.

10. Bristol City Council, 2016. Council and Mayor. Statistics and Census Information. The Population of Bristol.

11. Buffel, T., Phillipson, C. and Scharf, T., 2012. Ageing in urban environments: Developing 'age-friendly' cities. Critical Social Policy, 32(4) 597-617.

12. Börjesson, M., Eliasson, J., Hugosson, M. B. and Brundell-Freij, K., 2012. The Stockholm congestion charges - 5 years on. Effects, acceptability and lessons learnt. Transport Policy, 20, 1-12.

13. Börjesson, M., Eliasson, J. and Hamilton, C., 2016. Why experience changes attitudes to congestion pricing: The case of Gothenburg. Transportation Research Part A: Policy and Practice, 85, 1-16.

14. Chambré, S. M., and Einolf, C. J., 2008. Is volunteering work, prosocial behavior, or leisure? An empirical study. Working papers series/Chambre, S. Einolf, C., USA: Center for Nonprofit Strategy and Management.

15. Coria, J., Bonilla, J., Grundström, M. and Pleijel, H., 2015. Air pollution dynamics and the need for temporally differentiated road pricing. Transportation Research Part A: Policy and Practice, 75, 178-195.

16. DfT, 2001, Older people: Their transport needs and requirements - Summary report, Department for Transport, London.

17. DfT, 2016, Road Traffic Statistics, Bristol City, Department for Transport, London.

18. Di Ciommo, F., Monzón, A. and Fernandez-Heredia, A., 2013. Improving the analysis of road pricing acceptability surveys by using hybrid models. Transportation Research Part A: Policy and Practice, 49, 302-316.

19. Dominy, N. and Kempson, E., 2006. Understanding older people's experiences of poverty and material deprivation. Research Report No 363. Department for Work and Pensions, Leeds.

20. Dávila, M. C., and Díaz-Morales, J. F., 2009. Age and motives for volunteering: Further evidence. Europe's Journal of Psychology, 5(2), 82-95.

21. Ecola, L. and Light, T., 2010. Making congestion pricing equitable. Transportation Research Record: Journal of the Transportation Research Board, 2187, 53-59.

22. Eisma, R., Dickinson, A., Goodman, J., Syme, A., Tiwari, L. and Newell, A. F., 2004. Early user involvement in the development of information technology-related products for older people. Universal Access in the Information Society, 3(2), 131-140.

23. Eliasson, J. and Mattsson, L. G., 2006. Equity effects of congestion pricing: quantitative methodology and a case study for Stockholm. Transportation Research Part A: Policy and Practice, 40(7), 602-620.

24. Eliasson, J. and Jonsson, L., 2011. The unexpected "yes": Explanatory factors behind the positive attitudes to congestion charges in Stockholm. Transport Policy, 18(4), 636-647.

25. Eliasson, J., 2014. The role of attitude structures, direct experience and reframing for the success of congestion pricing. Transportation Research Part A: Policy and Practice, 67, 81-95.

26. Fennel, G., Phillpson, C. and Evers, H., 1993. The Sociology of Old Age. Philadelphia: Open University Press. 
27. Fern, E. F. 1982. The use of focus groups for idea generation: the effects of group size, acquaintanceship, and moderator on response quantity and quality. Journal of Marketing Research, 19(1), 1-13.

28. Fisk, A. D., Rogers, W. A., Charness, N., Czaja, S. J. and Sharit, J., 2009. Designing for Older Adults: Principles and Creative Human Factors Approaches. Boca Raton: CRC Press.

29. Fujii, S., Gärling, T., Jakobsson, C. and Jou, R. J., 2004. A cross-country study of fairness and infringement on freedoms as determinants of car owners' acceptance of road charging. Transportation, 31(3), 285-295.

30. Frey, B. S., 2003. Why are efficient transport policy instruments so seldom used. In: Schade, J. and Schlag, B. (eds.), Acceptability of Transport Pricing Strategies, 63-75.

31. Gaunt, M., Rye, T. and Allen, S., 2007. Public acceptability of road user charging: the case of Edinburgh and the 2005 referendum. Transport Reviews, 27(1), 85-102.

32. Gaffron, P., Hine, J. P. and Mitcell, F., 2001. The Role of Transport in Social Exclusion in Urban Scotland: Literature Review. Scottish Executive, Edinburgh.

33. Gehlert, T., Kramer, C., Nielsen, O. A. and Schlag, B. 2011. Socioeconomic differences in public acceptability and car use adaptation towards urban road pricing. Transport Policy, 18(5), 685-694.

34. Goerres, A. A., 2007. Why are older people more likely to vote? The impact of ageing on electoral turnout in Europe. British Journal of Politics and International Relations, 9(1), 90-121.

35. Goerres, A. A., 2008. The grey vote: Determinants of older voters' party choice in Britain and West Germany. Electoral Studies, 27(2), 285-304.

36. Goodwin, P., 2006. The gestation process for road pricing schemes. Local Transport Today, 444.

37. Grisolía, J. M., López, F. and de Dios Ortúzar, J., 2015. Increasing the acceptability of a congestion charging scheme. Transport Policy, 39, 37-47.

38. Guest, G., Namey, E., \& McKenna, K. 2017. How many focus groups are enough? Building an evidence base for nonprobability sample sizes. Field Methods, 29(1), 3-22.

39. Hensher, D. A. and Bliemer, M. C. J., 2014. What type of road pricing scheme might appeal to politicians? Viewpoints on the challenge in gaining the citizen and public servant vote by staging reform. Transportation Research Part A: Policy and Practice, $61,227-237$.

40. Hine, J. and Mitchell, F., 2003. Transport Disadvantage and Social Exclusion: Exclusionary Mechanisms in Transport in Urban Scotland. Aldershot: Ashgate.

41. Hofer, J., Busch, H., Au, A., Poláčková Šolcová, I., Tavel, P. and Tsien Wong, T., 2014. For the benefit of others: Generativity and meaning in life in the elderly in four cultures. Psychology and Aging, 29(4), 764.

42. Horne, C., 2001. Sociological perspectives on the emergence of norms. In: Hechter, M. and Opp, K. D., (eds). Social norms. Russell Sage Foundation, 3-34.

43. Hysing, E., 2015. Citizen participation or representative government - building legitimacy for the Gothenburg congestion tax. Transport Policy, 39, 1-8.

44. Ieromonachou, P., Potter, S., and Enoch, M. 2004. Adapting Strategic Niche Management for evaluating radical transport policies - the case of the Durham Road Access Charging Scheme. International Journal of Transport Management, 2(2), 75-87.

45. Ison, S. and Rye, T., 2005. Implementing road user charging: the lessons learnt from Hong Kong, Cambridge and Central London. Transport Reviews, 25(4), 1-15.

46. Jaensirisak, S., Wardman, M. and May, A. D., 2005. Explaining variations in public acceptability of road pricing schemes. Journal of Transport Economics and Policy, $39(2), 127-154$.

47. Jakobsson, C., Fujii, S. and Gärling,T., 2000. Determinants of private car users acceptance of road pricing. Transport Policy, 7(2), 153-158.

48. Johnson, P., Leicester, A., and Stoye, G. 2012. Fuel for Thought: the What, Why and How of Motoring Taxation. London: RAC Foundation. 
49. Joireman, J. A., Lasane, T. P., Bennett, J., Richards, D. and Solaimani, S. (2001). Integrating social value orientation and the consideration of future consequences within the extended norm activation model of proenvironmental behaviour. British Journal of Social Psychology, 40(1), 133-155.

50. Jones, P., 1998. Urban road pricing: public acceptability and barriers to implementation. In: Button K. J. and Verhoef E. T. (eds.) Road Pricing, Traffic Congestion and the Environment: Issues of Efficiency and Social Feasibility, Cheltenham, Edward Elgar Publishing, 263-284.

51. Jordan, K. and Avineri, E. 2008. Public representation in transport consultations: Exploring the age bias. Proceedings of the 40th Annual Universities' Transport Study Group Conference, January, Portsmouth, UK.

52. Kim, K. S., and Hwang, K. 2005. An application of road pricing schemes to urban expressways in Seoul. Cities, 22(1), 43-53.

53. King, D., Manville, M. and Shoup, D., 2007. The political calculus of congestion charging. Transport Policy, 14(2), 111-123.

54. Krueger, R., and M. Casey. 2015. Focus Groups: A Practical Guide for Applied Research. 5th ed. Thousand Oaks, CA: Sage.

55. Kovalchick, S., Camerer, C., Grether, D., Plott, C. and Allman J., 2004. Aging and decision making: a comparison between neurologically healthy elderly and young individuals. Journal of Economic Behavior and Organization, 58(2), 79-94.

56. Lang, F. R. and Carstensen, L. L., 2002. Time counts: future time perspective, goals, and social relationships. Psychology and Aging, 17(1), 125.

57. Langford, J., 2001. For many older drivers, mobility may be more important than safety. Australasian Road Safety Research, Policing and Education Conference, November, Melbourne, Australia.

58. Langmyhr, T., 1997. Managing equity. The case of road pricing. Transport Policy, 4(1), 25-39.

59. Lucas, K., 2006. Providing transport for social inclusion within a framework for environmental justice in the UK. Transportation Research Part A: Policy and Practice, 40(10), 801-809.

60. Manville, M. and King, D., 2013. Credible commitment and congestion pricing. Transportation, 40(2), 229-249.

61. May, A. D., Kelly, C. and Shepherd, S., 2006. The principles of integration in urban transport strategies, Transport Policy, 13(4), 319-327

62. May, A. D., Koh, A., Blackledge, D. and Fioretto, M., 2010. Overcoming the barriers to implementing urban road user charging schemes. European Transport Research Review, 2(1), 53-68.

63. Maxfield, M., Greenberg, J., Pyszczynski, T., Weise, D. R., Kosloff, S., Soenke, M. and Blatter, J., 2014. Increases in generative concern among older adults following reminders of mortality. The International Journal of Aging and Human Development, 79(1), 1-21.

64. McAdams, D. P., Hart, H. M. and Maruna, S., 1998. The anatomy of generativity. In: McAdams, D. P. and de St. Aubin, E. (eds.), Generativity and Adult Development, Washington, DC: American Psychological Association, 7-43.

65. Metz, D. H. (2000). Mobility of older people and their quality of life. Transport Policy, 7(2), 149-152.

66. Midlarsky, E., 1991. Helping as coping. In: Clark, M. S., (ed.) Prosocial Behavior. Newbury Park, CA: Sage, 238-264.

67. Morgan, D. L., 1997. Focus Groups as Qualitative Research. Qualitative Research Methods Series, $16,2^{\text {nd }}$ ed. London : A Sage University Paper.

68. Morrow-Howell, N., 2010. Volunteering in later life: Research frontiers. The Journals of Gerontology Series B: Psychological Sciences and Social Sciences, 65(4), 461-469.

69. Morselli, D. and Passini, S. 2015. Measuring prosocial attitudes for future generations: The social generativity scale. Journal of Adult Development, 22(3), 173-182. 
70. Musselwhite, C. B. A., 2006. Prolonging the Safe Driving of Older People through Technology: Attitudes of Older Drivers - Methodological Considerations. A study conducted for the Strategic Promotion of Ageing Research Capacity (SPARC).

71. Musselwhite, C. B. A. and Haddad, H., 2010. Mobility, accessibility and quality of later life. Quality in Ageing and Older Adults, 11(1), 25 - 37.

72. Niehaves, B. and Plattfaut, R., 2014. Internet adoption by the elderly: employing IS technology acceptance theories for understanding the age-related digital divide. European Journal of Information Systems, 23(6), 708-726.

73. Nikitas A., 2010. Understanding the Attitudes of Older People to Road Pricing. Doctorate Thesis, University of the West of England, Bristol, UK.

74. Nikitas, A., Avineri, E. and Parkhurst, G., 2011. Older people's attitudes to road charging: Are they distinctive and what are the implications for policy? Journal of Transportation Planning and Technology, 34(1), 87-108.

75. Nordbakke, S. and Schwanen, T. (2014). Well-being and mobility: A theoretical framework and literature review focusing on older people. Mobilities, 9(1), 104-129.

76. Noordegraaf, D. V., Annema, J. A. and van Wee, B., 2014. Policy implementation lessons from six road pricing cases. Transportation Research Part A: Policy and Practice, 59, 172-191.

77. Oliver, R. L. and Bearden, W. O., 1985. Crossover effects in the theory of reasoned action: a moderating influence attempt, Journal of Consumer Research, 12 (3), 324-340.

78. Organisation for Economic Co-operation and Development (OECD), 2013. Pensions at a Glance 2013: OECD and G20 Indicators. OECD Publishing.

79. Orimo, H., Ito, H., Suzuki, T., Araki, A., Hosoi, T. and Sawabe, M., 2006. Reviewing the definition of "elderly". Geriatrics \& Gerontology International, 6(3), 149-158.

80. Orski, C. K., 1992. Congestion pricing: promise and limitations. Transportation Quarterly, 46, 157-167.

81. Özkazanç, S., and Sönmez, F. N. Ö. 2017. Spatial analysis of social exclusion from a transportation perspective: A case study of Ankara metropolitan area. Cities, 67, 74-84.

82. Park, S. and Smardon, R. C., 2009. Intergenerational differences in values and dioxin risk perceptions in South Korea. Management of Environmental Quality: An International Journal, 20(5), 522-537.

83. Parkhurst, G. 2002. The top of the escalator? In Lyons, G., Chatterjee, K., (eds), Transport Lessons from the Fuel Tax Protests of 2000. Aldershot: Ashgate, 299-321.

84. Parkhurst, G., Galvin, K., Musselwhite, C., Phillips, J., Shergold, I. and Todres, L. 2014. Beyond transport: Understanding the role of mobilities in connecting rural elders in civic society. In: Hennessey, C., Means, R. and Burholt, V., eds. (2014) Countryside Connections: Older People, Community and Place in Rural Britain. Bristol: Policy Press, 125-157.

85. Peek, S. T., Wouters, E. J., van Hoof, J., Luijkx, K. G., Boeije, H. R. and Vrijhoef, H. J., 2014. Factors influencing acceptance of technology for aging in place: a systematic review. International Journal of Medical Informatics, 83(4), 235-248.

86. Preston, J., 2012. Public transport subsidisation. In: Ison S. and Rye, T. (eds.), The Implementation and Effectiveness of Transport Demand Management Measures: An International Perspective. Aldershot: Ashgate.

87. Prince, M. J., Wu, F., Guo, Y., Robledo, L. M. G., O'Donnell, M., Sullivan, R. and Yusuf, S., 2015. The burden of disease in older people and implications for health policy and practice. The Lancet, 385(9967), 549-562.

88. Pronello, C. and Rappazzo, V., 2014. Road pricing: How people perceive a hypothetical introduction. The case of Lyon. Transport Policy, 36, 192-205.

89. Raje, F., 2003. The impact of transport on social exclusion processes with specific emphasis on road user charging. Transport Policy, 10, 321-338.

90. Rajé, F., Grieco, M., Hine, J. and Preston, J. 2004. Transport, demand management and social inclusion: The need for ethnic perspectives. Aldershot: Ashgate. 
91. Raymundo, T. M. and da Silva Santana, C., 2014. Factors Influencing the Acceptance of Technology by Older People: How the elderly in Brazil feel about using electronics. IEEE Consumer Electronics Magazine, 3(4), 63-68.

92. Richardson, T., Isaksson, K. and Gullberg, A., 2010. Changing frames of mobility through radical policy interventions? The Stockholm congestion tax. International Planning Studies, 15 (1), 53-67.

93. Rosenbloom, S., 2001. Sustainability and automobility among the elderly: An international assessment. Transportation, 28, 375-408.

94. Santos, G., and Rojey, L., 2004. Distributional impacts of road pricing: The truth behind the myth. Transportation, 31(1), 21-42.

95. Schade, J., and Schlag, B., 2003. Acceptability of urban transport pricing strategies. Transportation Research Part F: Traffic Psychology and Behaviour, 6(1), 45-61.

96. Schade, J., and Baum, M., 2007. Reactance or acceptance? Reactions towards the introduction of road pricing. Transportation Research Part A: Policy and Practice, 41(1), 41-48.

97. Scharf, T., Phillipson, C. and Smith, A. E., 2005. Social exclusion of older people in deprived urban communities of England. European Journal of Ageing, 2(2), 76-87.

98. Schmöcker, J. D., Pettersson, P. and Fujii, S., 2012. Comparative analysis of proximal and distal determinants for the acceptance of coercive charging policies in the UK and Japan. International Journal of Sustainable Transportation, 6(3), 156-173.

99. Schuitema, G., Steg, L. and Forward, S., 2010. Explaining differences in acceptability before and acceptance after the implementation of a congestion charge in Stockholm. Transportation Research Part A: Policy and Practice, 44(2), 99-109.

100. Scottish Executive, 2006. Evaluation of Edinburgh residents' attitudes to the proposed road user charging scheme. Edinburgh: Transport Research Series.

101. Seik, F. T. 2000. An advanced demand management instrument in urban transport: electronic road pricing in Singapore. Cities, 17(1), 33-45.

102. Selwyn, N., 2004. The information aged: A qualitative study of older adults' use of information and communications technology. Journal of Aging Studies, 18, 369-384.

103. Shergold, I., and Parkhurst, G., 2012. Transport-related social exclusion amongst older people in rural Southwest England and Wales. Journal of Rural Studies, 28, 412-421.

104. Shergold, I., Parkhurst, G. and Musselwhite C. B. A., 2012. Rural car dependence: an emerging barrier to community activity for older people. Journal of Transportation Planning and Technology, 35(1), 69-85.

105. Siren, A. and Hakamies-Blomqvist, L., 2004. Private car as the grand equaliser? Demographic factors and mobility in Finnish men and women aged 65+. Transportation Research Part F: Traffic Psychology and Behaviour, 7, 107-118.

106. Social Exclusion Unit (SEU), 2003. Making the connections: transport and social exclusion final report. London, UK. Available from: http://www.ilo.org/wcmsp5/groups/public/@ed_emp/@emp_policy/@invest/documents/ publication/wcms_asist_8210.pdf [Accessed 16/12/2016].

107. Sochor, J., 2014. The reassuring effects of ICT in public transportation: The perspectives of older adults. Proceedings of the 93rd Annual Meeting of the Transportation Research Board, Washington, D.C., January 12-16, 2014.

108. Sochor, J. and Nikitas, A., 2016. Vulnerable users' perceptions of transport technologies. Proceedings of the Institution of Civil Engineers: Urban Design and Planning, 169(3), 154-162.

109. Sørensen, C. H., Isaksson, K., Macmillen, J. and Åkerman, J., 2014. Strategies to manage barriers in policy formation and implementation of road pricing packages. Transportation Research Part A: Policy and Practice, 60, 40-52.

110. Tabuchi, M. and Miura, A., 2015. Young people's reactions change elderly people's generativity and narratives: The effects of intergenerational interaction on the elderly. Journal of Intergenerational Relationships, 13(2), 118-133.

111. Tallon, A. R. 2007. Bristol. Cities, 24(1), 74-88. 
112. Timilsina, R., Kotani, K., \& Kamijo, Y. 2016. Generativity and social value orientation between rural and urban societies. Social Design Engineering Series, 2016-11, Kochi University of Technology.

113. TomTom, 2016. Measuring Congestion Worldwide: Bristol, United Kingdom. Available from: https://www.tomtom.com/en_gb/trafficindex/city/BRO [Accessed 01/07/2017].

114. Urry, J., 2012. Sociology beyond Societies: Mobilities For The Twenty-First Century. Routledge.

115. Vaismoradi, M., Turunen, H., \& Bondas, T., 2013. Content analysis and thematic analysis: Implications for conducting a qualitative descriptive study. Nursing \& Health Sciences, 15(3), 398-405.

116. Van Lange, P. A. M., Otten, W., De Bruin, E. M. N. and Joireman, J. A., 1997. Development of prosocial, individualistic and competitive orientations: theory and preliminary evidence. Journal of Personality and Social Psychology, 73 (4), 733-746.

117. Van Oorschot, W., Arts, W. and Halman, L., 2005. Welfare state effects on social capital and informal solidarity in the European Union: Evidence from the 1999/2000 European Values Study. Policy \& Politics, 33(1), 33-54.

118. Webber, S. C., Porter, M. M. and Menec, V. H., 2010. Mobility in older adults: a comprehensive framework. The Gerontologist, 50(4), 443-450.

119. Winslott-Hiselius, L., Brundell-Freij, K., Vagland, A. and Byström, C., 2009. The development of public attitudes towards the Stockholm congestion trial. Transportation Research Part A: Policy and Practice, 43(3), 269-282.

120. World Health Organization, 2017a. Definition of an Older or Elderly Person. Health Statistics and Health Information Systems (online). Available from: http://www.who.int/healthinfo/survey/ageingdefnolder/en/index.html [Accessed 01/06/2017].

121. World Health Organization, 2017b. Ageing and Life Course (online). Available from: http://www.who.int/ageing/en/ [Accessed 01/06/2017].

122. Young, R. and West, P. (2010). Do 'good values' lead to 'good' health-behaviours? Longitudinal associations between young people's values and later substance-use. $B M C$ Public Health, 10(1), 165. 


\section{Appendix:}

\section{Focus Group Topic Guide:}

Introduction (5 mins):

- Welcome.

- Thank the participants.

- Researcher's introduction.

- Associate helping out with the focus groups to be introduced.

- Health and Safety Instructions.

- Reminder of the voucher for the travel costs and time compensation that will be given at the end of the sessions.

- Brief description of the research objectives.

- Introducing the concept of focus group and the procedure to be followed

- Review the ground rules: everyone's ideas are important and everyone will be given an opportunity to speak. There are no right or wrong answers; even negative comments are useful in gaining insight about the topic under discussion.

- Reminder that the session will be recorded.

- Note that the whole process is confidential; anonymity will be kept, no individual will be identified by name or any other way, and that all the audio recordings, transcriptions, forms or other material will be destroyed at the end of the research.

- Provision of contact details.

- Any initial questions before the focus group start?

Ice Breaker (2-3 mins):

- Everybody to introduce themselves

- First name.

- Occupation.

- How often drive/travel with a car/ other modes.

Background Discussion Items (10 mins):

- Start a circle discussing people's thoughts around road pricing.

- People to share their thoughts and experiences.

- Examine knowledge (awareness) of road pricing issues including the following questions

- Were you aware about road pricing prior the survey?

- Have you had any more thoughts about road pricing after the survey?

Introduction of a scenario-type approach in which the focus group participants will be presented with specific road pricing visions (10 mins)

- Stress out that this is a hypothetical scheme used for this research exercise only.

- Explain that the scheme chosen was an older road pricing plan that did not go on.

- Any questions?

Attitudes to Road Pricing (20mins):

Focused Road Pricing Questions about Own Attitudes

- Do you find this scheme to be fair/good/effective?

- Why do you think that?

- Is there any particular reason for this? 
Focused Road Pricing Questions Examining the Ageing Effect on Attitudes

- One survey respondent quoted that: "My answers are dictated by my age and retirement. If I was younger these could be a lot different".

- Do you agree with that?

- What role does age play on the way you view road pricing?

Social Norms, Pro-Social Value Orientations and their Influence on Attitudes to Road Pricing (30 mins):

Identification of Social Norms in the Context of Road Pricing:

- Try for a minute to think what the people close to you would think about this scheme

- Would you think they would consider it fair/good/effective?

- How much would their views about road pricing influence your opinion about road pricing?

- If they were in favour of road pricing would you be more likely to be in favour of road pricing yourself? Why is that?

- If you were younger/older would their attitudes influence you the same?

- When you expressed your opinion about the fairness/goodness/effectiveness of road pricing did you think of the people important to you and their potential views?

Identification of Pro-social Values in the Context of Road Pricing:

- One of the respondents the other day claimed that: 'I would support road pricing if it is beneficial for the people most important to me and for the people living in Bristol in general'.

- What do you think about that?

- Would you consider doing the same or are you of a different opinion?

- When you expressed your opinion about the fairness/goodness/effectiveness of road pricing did you think of that?

- If you were younger/older would this influence you the same?

- Do you trust that road pricing could be beneficial for the people close to you and in general for other people living in Bristol? If not why?

- What would it take for you to decide that road pricing could be genuinely a measure beneficial for the people most important to you and society in general?

Focused Road Pricing Questions Relating Attitudes with Other Factors (10 mins)

Identification of Geo-spatial and Income Effects:

- Would your opinion about road pricing be any different if you were leaving closer/further away from the hypothetical road pricing scheme?

- Would your opinion about road pricing be any different if you had higher/lower income?

Additional Questions (5mins):

Focused Road Pricing Questions about Generated Revenue Expenditure

- How would you like to see the revenue generated spent?

- If the money will be spent in the right way (re-invested in transport) would you be more positive to a road pricing scheme?

Identification of Media and Government' s Influence:

- Discuss whether and if so how much, the Media or/and the National Government/Local Authorities can potentially influence your opinion 
Summing Up (5 mins):

- Use of a "cooling down" exercise asking group members to say one thing that they heard that was really important.

- Thank all the focus group participants for their time and effort.

- Reminder that the use of all the information collected will be confidential.

- Ask the participants whether they want to receive a follow-up (perhaps be generally informed about the conclusions of the study).

- Hand down tokens of appreciation for their participation in the study 